УДК $62-868.8$

${ }^{[0000-0003-1727-3286] ~ С . ~ О . ~ Ф і л і м о н о в, ~ к . т . н ., ~ д о и е н т, ~}$ e-mail: s.filimonov@chdtu.edu.ua

С. С. Ященко,

${ }^{[0000-0001-8920-0743]}$ О. В. Батраченко, к.т.н., дочент, e-mail:avbatrachenko1980@gmail.com

[0000-0001-9241-1760] Н. В. Філімонова, к.т.н., старший викладач

e-mail: nv.filimonova2015@gmail.com

Черкаський державний технологічний університет

б-р Шевченка, 460, м. Черкаси, 18006, Україна

\title{
РОЗРАХУНОК СИЛ, ЩО ВИНИКАЮТЬ ПРИ СТВОРЕННІ ВІБРАЦІЙ ЗА ДОПОМОГОЮ SMART PIEZOCERAMICS, ТА ДОСЛІДЖЕННЯ ЇХ РОЗПОДІЛУ У ПЛУЖНОМУ ВІДВАЛІ
}

Однією з головних проблем сільського господарства є складність та ефективність обробки землі. У статті на основі аналізу літературних джерел і наукових публікаиій визначено недоліки класичних плугів та віброплугів, зокрема основні недоліки конструкиії віброплуга на основі smart piezoceramics. Основною метою статті є розрахунок та визначення необхідної сили smart piеzосегатісs для створення вібраџій у плужному відвалі, а також проведення моделювання на основі проведених розрахунків.

Ключові слова: сільське господарство, вібраційні технологї̈, моделювання, smart ріеzосегатісs, розрахунки, принцип роботи, аналіз, продовольча безпека, проблеми, рімення.

Сільське господарство є однією 3 найважливіших галузей, що забезпечує населення продовольчими товарами і сировиною для ряду галузей промисловості. Від стану сільського господарства залежить продовольча безпека держави та її громадян.

Однією з головних проблем сільського господарства $\epsilon$ складність та ефективність обробки землі. Процес розпушення грунтового середовища клином є одним із найбільш поширених способів поліпшення його властивостей [1]. Оранка, або полицевий спосіб обробляння грунту, полягає у підрізанні оброблюваної скиби, iї підніманні з розпушенням і обертанням на 130-180 \% та укладанні на дно попередньо відкритої борозни. Цей спосіб характеризується повним очищенням поверхні поля від післяжнивних решток (на 95-100\%), загортанням у грунт органічних, мінеральних добрив, бур'янів, значним зменшенням щільності орного шару та збільшенням його поруватості [2].

У зв'язку з тим, що оранка супроводжується деформацією, руйнуванням і переміщенням грунтового шару, витрати енергії на виконання операції $\epsilon$ порівняно великими. За енергетичними витратами оранка $є$ найбільш енергоємною операцією у технологічному процесі вирощування сільськогосподарських культур [3]. Розпушування землі відбувається зазвичай за рахунок використання звичайних плугів.

Тому вдосконалення саме головних пристроїв культивації грунту є надійним способом покращення ефективності обробки землі.

У відомих начіпних плугах загального призначення до рами болтовим 3'єднанням кріпляться стояки корпусів плуга 3 корпусом. Під час роботи орного агрегату тяговий опір плуга здійснює коливання, які збільшують динамічні навантаження вузлів та деталей, що призводять до передчасного їх руйнування. Крім цього, під час коливальних рухів орного агрегату збільшується зусилля трактора на його переміщення, що призводить до підвищення тягового опору.

Одним із різновидів плуга є віброплуг [4]. На рисунку 1 зображено функціональну схему вібраційного плуга. Вібраційний плуг складається 3 корпусу 1, стояка корпусу 2, який з'єднаний з рамою 3 за допомогою шарніра 4. На рамі плуга 3 під змінним кутом $\alpha$ закріплений вібратор 5, що штоком 6 3'єднаний зі стояком корпусу 2. Вібратор 5 складається 3 поршня 7, виготовленого разом зі штоком 6, і золотника 8. Порожнина вібратора 5 під'єднана до гідросистеми трактора.

(c) С. О. Філімонов, С. С. Ященко, О. В. Батраченко, Н. В. Філімонова, 2020 DOI: $10.24025 / 2306-4412.2 .2020 .198180$ 
Дроселем 9 забезпечується регулювання частоти коливань вібратора 5 [4].

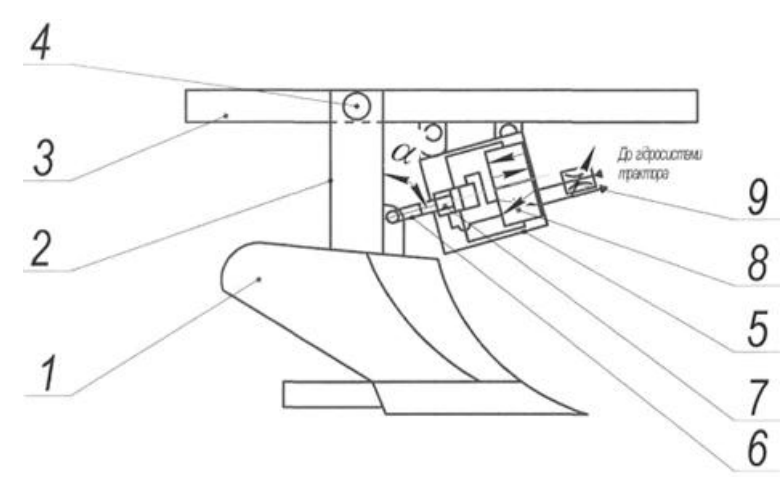

Рисунок 1 - Функціональна схема вібраційного плуга

Ці вдосконалення мають ряд недоліків: збільшення ваги робочого органу, зменшення часу експлуатації вібраційного вузла, підвищення складності обслуговування та виготовлення виробу тощо.

При додаванні додаткових механічних пристроїв їх характеристики та недоліки накладаються на сам орган обробки грунту (плуг).

На практиці найчастіше виходять із ладу саме механічні частини пристроїв, i чим їх більше, тим більший ризик виходу 3 ладу однієї з цих частин. Тим паче, коли пристрій або орган, який бере участь у цьому випадку в обробці землі, повинен витримувати великі фізичні навантаження, - цей фактор збільшує ризики зменшення зносостійкості матеріалів.

В іншій роботі [5] наведений приклад вібраційного плуга, в основі якого лежить використання smart piezoceramics як актуатоpa (вібратора), принцип роботи якого полягає в наступному: при подачі змінної електричної напруги за рахунок зворотного п'єзоефекту в п'єзоелементі виникають коливання, які передаються плужному відвалу. Таким чином, у плузі виникає вібрація, яка сприяє зменшенню сили тертя плуга 3 грунтом. При відключенні змінної електричної напруги за рахунок прямого п'єзоефекту п’єзоелемент виступає як датчик, отримані значення якого використовуються для корекції амплітуди коливань вібрації.

На рисунку 2 представлена конструкція плугового відвалу зі smart piezoceramics [5].

Однак при розробці вібраційного плуга на основі smart piezoceramics автори не наводять розрахунків для визначення необхідних параметрів їх силових складових.

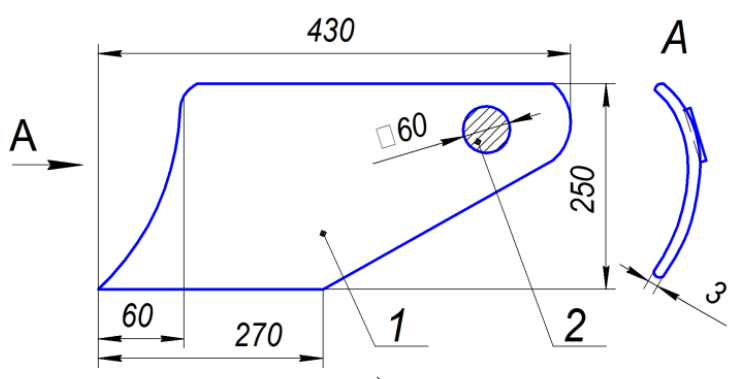

a)

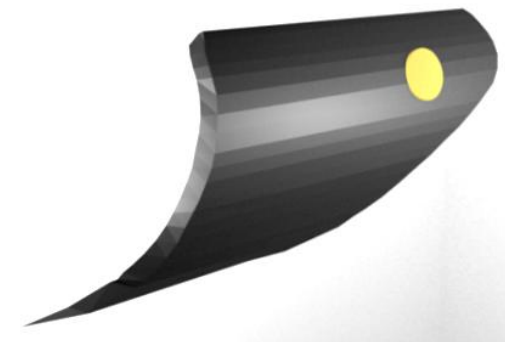

б)

a) складальне креслення; б) вид 3D;

1 - відвал; 2 - елемент smart piezoceramics

Рисунок 2 - Плужний відвал iз smart piezoceramics

Метою роботи є визначення необхідної створюваної сили smart piezoceramics для створення коливань у віброплузі, а також власних коливань плуга.

Для визначення необхідної генерації створюваної сили smart piezoceramics необхідно знати величину сили, яка діє на плуг, а також резонансні частоти коливань плуга під час оранки. Ця сила буде рівнозначна силі, необхідній для тяги плуга.

Визначення необхідної створюваної сили smart piezoceramics. Для визначення сили, необхідної для тяги плуга, засновник землеробної механіки академік Василь Прохорович Горячкін запропонував формулу, що розкриває закономірності i фізичний зв'язок між основними факторами робочого процесу плуга i загальним опором, що виникає при його роботі. Ці залежності записані в раціональному вигляді, тому й сама формула названа раціональною $[6,7]$. Вона має вигляд (1)

$$
P_{x}=f \cdot G+\left(k \cdot a \cdot b+\varepsilon \cdot a \cdot b \cdot u^{2}\right) \cdot n,
$$

де $f$ - коефіцієнт, аналогічний коефіцієнту тертя; $G$ - сила тяжіння плуга, H; $k$ - коефіцієнт питомого опору грунту, Па; $a$ та $b-$ розміри перетину пласта, м; $\varepsilon$ - безрозмірний коефіцієнт, що залежить від форми відвалу і властивостей грунту; $v$ - швидкість, м/с; $n-$ кількість корпусів плуга. Коефіцієнт корисної дії плуга визначається за формулою

(C) C. О. Філімонов, С. С. Ященко, О. В. Батраченко, Н. В. Філімонова, 2020 DOI: $10.24025 / 2306-4412.2 .2020 .198180$ 


$$
\eta=\frac{\left(k \cdot a \cdot b+\varepsilon \cdot a \cdot b \cdot v^{2}\right) n}{f G+\left(k \cdot a \cdot b+\varepsilon \cdot a \cdot b \cdot v^{2}\right) n} .
$$

Визначення коефіцієнтів $f, k$ і $\varepsilon$ раціональної формули В. П. Горячкіна проводиться за формулами (3)-(5) [6, 7]:

$$
\begin{gathered}
\mathrm{f}=\frac{\mathrm{P}_{1}}{\mathrm{G}}, \\
k=\frac{q \cdot l-m \cdot r}{n \cdot l-m^{2}}, \\
\varepsilon=\frac{n \cdot r-q \cdot m}{n \cdot l-m^{2}} .
\end{gathered}
$$

Розрахункове зусилля на плуг визначається за формулою

$$
\mathrm{P}_{\text {pосч }}=v \cdot \mathrm{P}_{\mathrm{x}} \text {. }
$$

Розрахункове зусилля на один корпус рекомендується визначати за виразом

$$
P_{\text {pacu }}^{0}=\frac{P \mathrm{x}}{n}[n(v-1)+1],
$$

де $n$ - кількість корпусів плуга.

Виходячи 3 формул (1)-(5) В. П. Горячкіна, було визначено складові сили, необхідні для тяги однокорпусного плуга $n=1$.

Для розрахунків використовувалися та-

\begin{tabular}{|c|c|c|}
\hline $\begin{array}{c}\text { Характеристика } \\
\text { грунту }\end{array}$ & $\begin{array}{c}\text { Питомий } \\
\text { опір при } \\
\text { оранці, } \\
\text { кН/м² }\end{array}$ & $\begin{array}{l}\text { Вологість } \\
\text { грунту, \% }\end{array}$ \\
\hline $\begin{array}{l}\text { Дуже легкі, піщані } \\
\text { i супіщані, м’які }\end{array}$ & 20 & $18 \ldots .22$ \\
\hline $\begin{array}{l}\text { Легкі, супіщані, } \\
\text { злежані, хрящуваті }\end{array}$ & 30 & $18 \ldots .22$ \\
\hline $\begin{array}{l}\text { Легкі, супіщані, } \\
\text { суглинні, підвище- } \\
\text { ної вологості }\end{array}$ & 40 & $30 \ldots 25$ \\
\hline $\begin{array}{l}\text { Суглинні, хрящу- } \\
\text { ваті, кам'янисті, } \\
\text { злежані }\end{array}$ & $45-50$ & 35 \\
\hline $\begin{array}{l}\text { Важко суглинисті і } \\
\text { глинисті, що не } \\
\text { злежані }\end{array}$ & $50-60$ & $18 \ldots 22$ \\
\hline
\end{tabular}
кі дані: сила тяжіння плуга $G=47 \mathrm{H}$; розміри перерізу пласта $a=0,2 \mathrm{м}, b=0,35 \mathrm{м}$; швидкість $v=1,5 \mathrm{~m} / \mathrm{c} ; m=4,7$ кг, $P_{1}=235 \mathrm{H}, l=0,43, n=1$.

Таблиця 1 - Коефіціснт питомого опору грунту [8]

За формулою (3) було розраховано коефіцієнт тертя $f=0,5$; коефіцієнт питомого опо- ру грунту було взято 3 таблиці 1 [8] $k=41000 \mathrm{H} / \mathrm{m}^{2}$ (легкий, супіщаний, злежаний, хрящуватий грунт); за формулою (1) було розраховано силу, необхідну для тяги плуга $P_{x}=3,2 \kappa \mathrm{H}$.

На основі розрахункових даних у пакеті програм Solid Works було проведено візуальне моделювання розподілення зовнішніх сил на плуг.

Застосування пакета SolidWorks для візуального моделювання було обумовлено можливостями цієї системи гібридного параметричного моделювання здійснювати проектування деталей у тривимірному просторі 3 подальшим проведенням різних видів експрес-аналізу, а також оформлення конструкторської документації [10].

Також перевагою застосування цього програмного пакета була можливість реалізувати моделювання фізико-механічних процесів за рахунок модуля Simulation, оскільки SolidWorks Simulation $є$ універсальним інструментом для аналізу методом кінцевих елементів.

Як вихідні дані для моделювання було враховано, що в процесі оранки на плуг діють сили за всіма координатними осями, а саме: в напрямку переміщення корпусу плуга $-R x, \mathrm{y}$ горизонтальній площині, перпендикулярній переміщенню плуга, $-R y$ i у вертикальній площині $-R z$ [9].

Сили $R x, R y$ і $R z$ залежать від властивостей грунту, глибини оранки, швидкості руху, геометричної форми поверхні корпусу, гостроти леза лемеша та ін.

Ці залежності складні і поки що не всі вивчені.

У більшості випадків бічна сила $R y$ становить приблизно $1 / 3$ від сили $R x$, а вертикальна сила $R z$ є змінною та може набувати як додатних, так і від'ємних значень. Середнє іiі значення приймають рівним $\pm 0,2 R x$.

На рисунках 3-5 зображено проекції рівнодіючих елементарних опорів грунту на площині проекції XOZ (рисунок 3), XOY (рисунок 4) і $Y O Z$ (рисунок 5) відповідно [9].

Значення сили (розрахованої вище, $P_{x}$ ), що прикладене до плуга в напрямку переміщення корпусу плуга - $R x$, становить 3,2 кН, а бічна сила $R y$ становить 1 кН.

Було проведено визначення розподілення напружень на плуг при оранці (рисунок 6). 


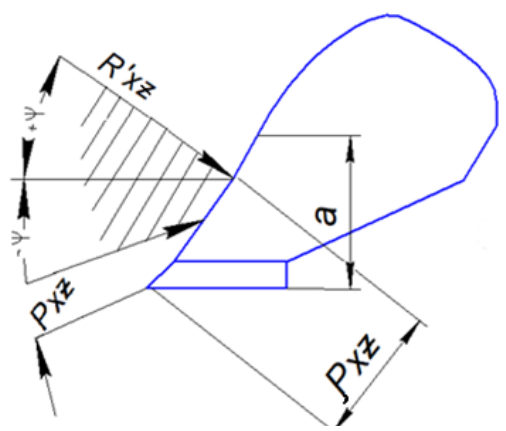

Рисунок 3 - Сили, що діють на корпус плуга, в поздовжньо-вертикальній площині

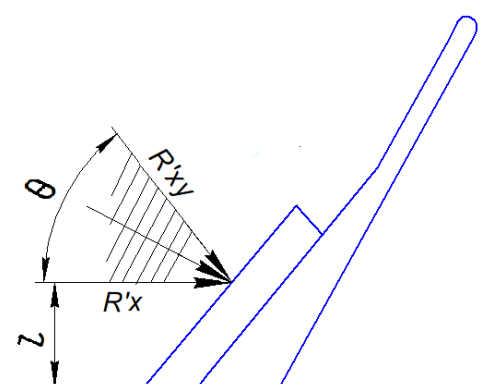

Рисунок 4 - Сили, що діють на корпус плуга, в горизонтальній площині

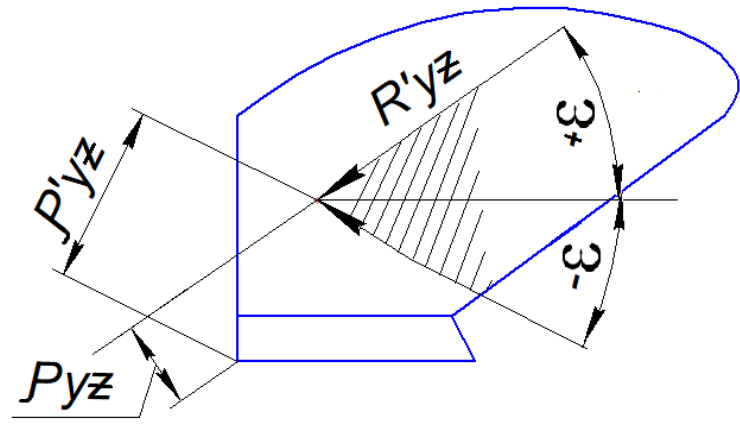

Рисунок 5 - Сили, що діють на корпус плуга, в поперечно-вертикальній площині

На рисунку 7 показано амплітудні переміщення частин плуга при оранці.

3 рисунка 7 видно, що максимальні коливання плуга при оранці становлять 1,97 мм.

Окрім цього, було визначено перші п’ять резонансних частот плуга при оранці.

Результати моделювання зображено на рисунку 8.

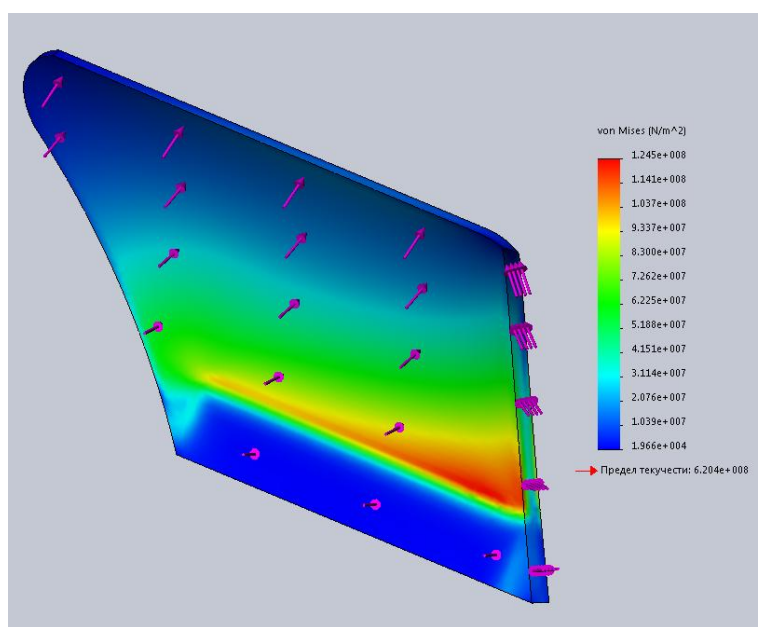

Рисунок 6 - Напружено-деформований стан плуга при оранці (значення коефіцієнта запасу міцності)

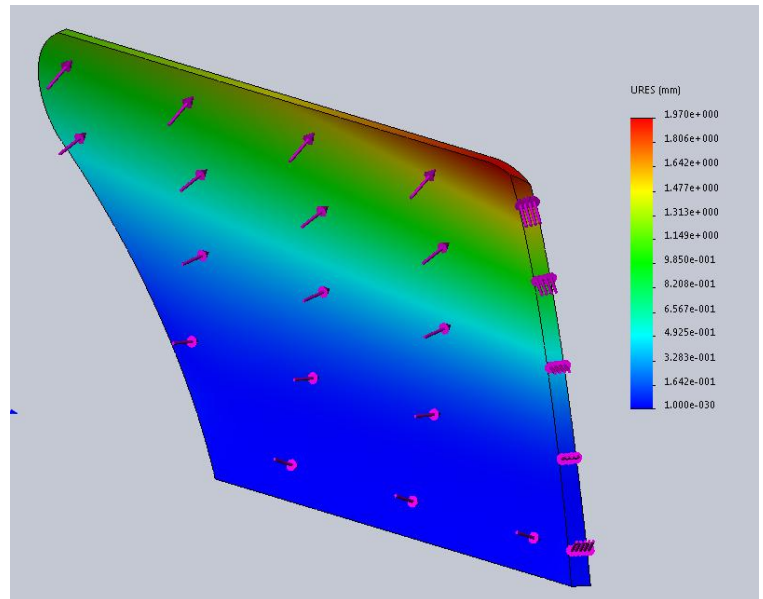

Рисунок 7 - Амплітудні переміщення частин плуга при оранці

(C) C. О. Філімонов, С. С. Ященко, О. В. Батраченко, Н. В. Філімонова, 2020 DOI: $10.24025 / 2306-4412.2 .2020 .198180$ 


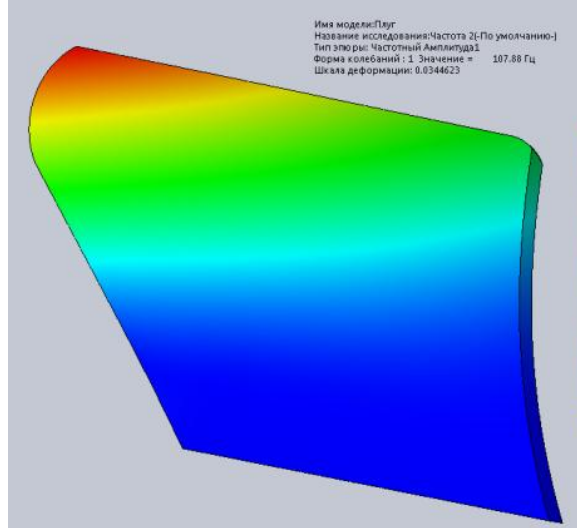

a)

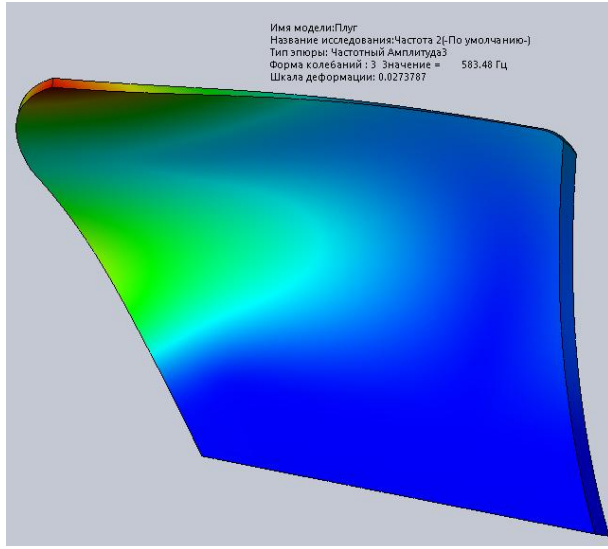

в)

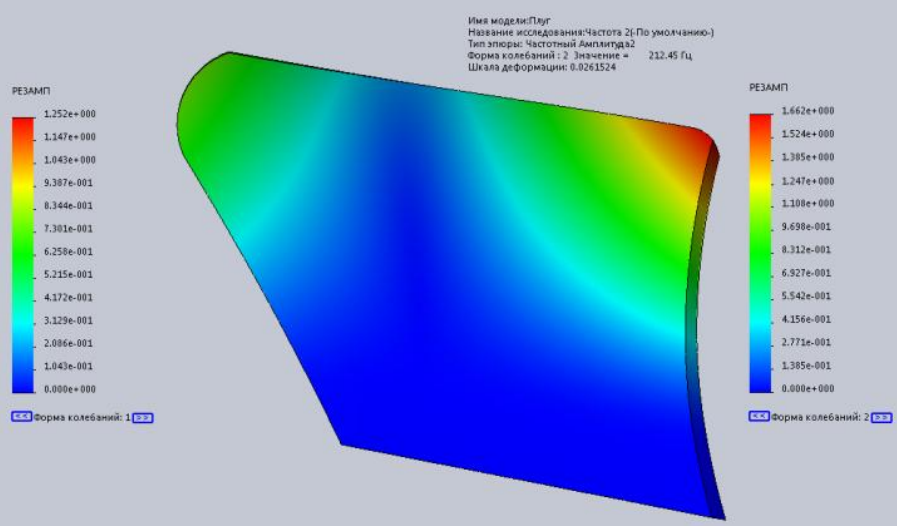

б)

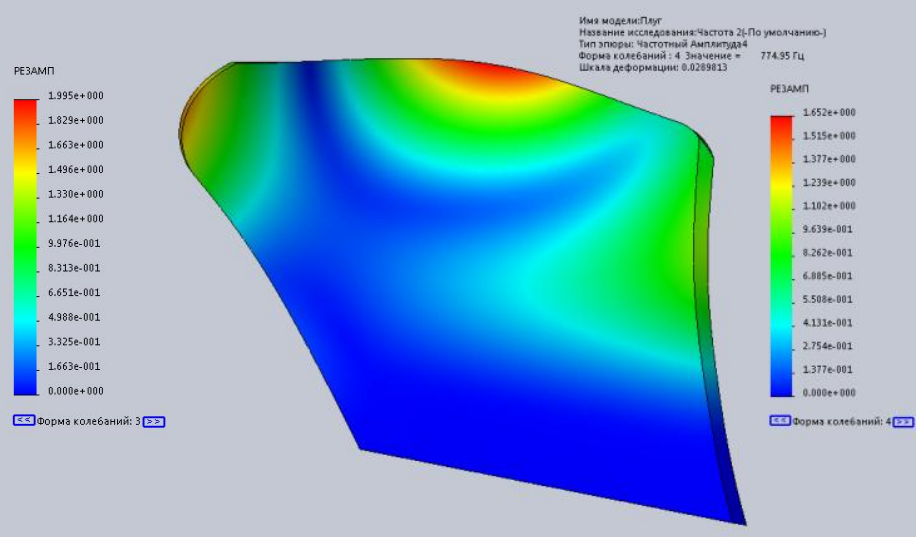

2)

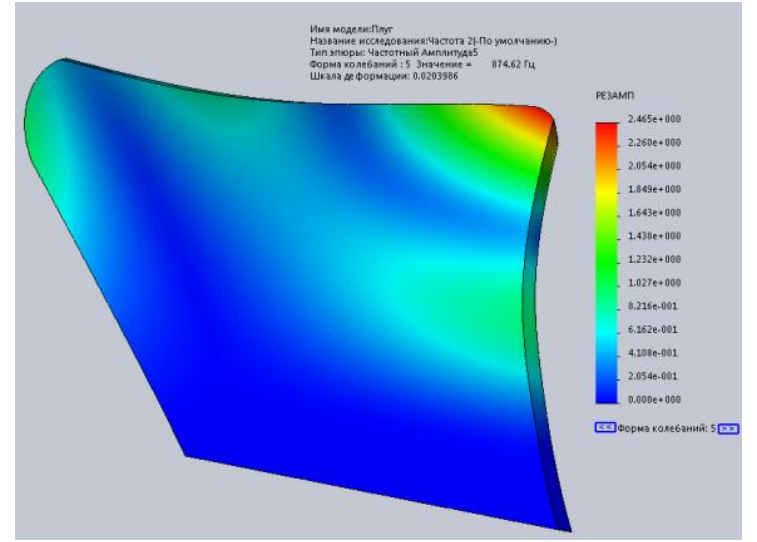

d)

a) 107,88 Гц, б) 212,45 Гц, в) 583,48 Гц, г) 774,94 Гц, д) 874,62 Гц

Рисунок 8 - Результати моделювання коливання плуга під час оранки в пакеті програм SolidWorks на різних частотах

Для найбільш наочного аналізу амплітуди коливань плуга під час оранки побудуємо графік залежності амплітуди коливань (безрозмірна величина) від частоти (рисунок 9).

3 рисунка 9 видно, що максимальній амплітуді коливань відповідає частота 874,6 Гц.

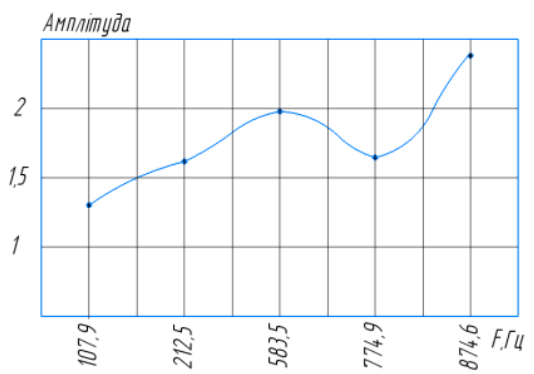

Рисунок 9 - Графік залежності амплітуди коливань плуга при оранці від частоти 
Висновки. Таким чином, у роботі проведено розрахунки на визначення необхідної створюваної сили smart piezoceramics для створення коливань у віброплузі, яка становить 3,2 кН. Також проведено моделювання за допомогою пакета програм SolidWorks у модулі Simulation. Визначено частоту, за умови якої можливо спостерігати максимальні коливання (вібраціі) плужного відвала, при оранці плугом, що становить 107,88 Гц. Крім цього, знайдено амплітуду коливань та напруженодеформований стан плуга при оранці, тобто значення коефіцієнта запасу міцності, що дасть можливість в подальшому оптимально визначати місце розташування smart piezoceramics для отримання максимального ефекту вібрації.

\section{Список використаних джерел}

[1] Я. С. Гуков, Обробіток трунту. Технологія і техніка. Механіко-технологічне обтрунтування енергозберігаючих засобів для механізащії обробітку трунту в умовах України. Київ: Нора-прінт, 1999.

[2] Д.Г. Войтюк, В. О. Дубровін, та Т. Д. Іщенко, Сільськогосподарські та меліоративні машини. Київ: Вища освіта, 2004.

[3] А. Б. Лурье, и А. А. Громбчевский, Рacчет и конструирование сельскохозяйственных машин. Ленинград: Машиностроение, 1977.

[4] В. С. Ловейкін, Ю. В. Човнюк та Л. А. Дяченко, "Вібраційний плуг", Пат. 57793 Украӥна, МПК2011.01 АО1В 63/111. № U201010563; заявл. 31.08.2010; опубл. 10.03.2011, Бюл. № 5 .

[5] С. О. Филимонов, С. С. Ященко, А. В. Батраченко, и Н. В. Филимонова, "Использование SMART PIEZOCERAMICS для обработки почвы в сельском хозяйстве", Bicник Черкаського державного технологічного університету, № 2, с. 30-36, 2019.

[6] И. И. Максимов, "Рациональная формула В. П. Горячкина для определения тягового сопротивления плуга", в Практикум по сельскохозяйственным матинам $u$ орудиям. Чебоксары, 2011. [Электронный pecypc]. Режим доступа: https://studfile. net/preview/5719257/page:33. Дата обращения: Февр. 02, 2020.

[7] В. Б. Самородов, и А. Ю. Ребров, "Развитие классических методов тягового рас- чета трактора с учетом основных техникоэкономических показателей МТА", $B i$ сник Національного технічного університету «Харківський політехнічний інстиmут»: зб. наук. праць. Тем. вип.: Автомобіле- $і$ тракторобудування, № 58, с. 11-20, Харків: НТУ «ХПІ», 2008.

[8] А. П. Дорохов, Э. Г. Мухамадиев, и Н. А. Печерцев (сост.), Методические указания к выполнению контрольной работы по курсу «Эксплуатация машиннотракторного парка» (для студентов факультета заочного образования). Челябинск: ЧГАА, 2010.

[9] А. Ю. Попов, Машины и оборудование в растениеводстве: учеб. пособие. Зерноград: Азово-Черноморский инжен. ин-т ФГБОУ ВО Донской ГАУ, 2016.

[10] Н. А. Языков, А. А. Топоров, Л. И. Рублева, и В. Ю. Левандовский, "Моделирование гидродинамических процессов в реакторе для интенсификации химической очистки сточных вод от фенолов с помощью программного модуля SolidWorks Flow Simulation", Наукові праичі Донециького національного технічного університету. Серія «Хімія $і$ хімічна технологія», вип. 14, 2012.

\section{References}

[1] Ya. S. Gukov, Soil cultivation. Technology and machinery. Mechanical and technological substantiation of energy saving tools for mechanization of soil tillage in the conditions of Ukraine, Kyiv: Noraprint, 1999 [in Ukrainian].

[2] D. G. Voituk, V. O. Dubrovin, and T. D. Ishchenko, Agricultural and reclamation machines. Kyiv: Vyshcha osvita, 2004 [in Ukrainian].

[3] A. B. Lurie, and A. A. Grombchevsky, Calculation and design of agricultural machinery. Leningrad: Mashinostroyenie, 1977 [in Russian].

[4] V. S. Loveykin, Yu. V. Chovnyuk, and L. A. Dyachenko, "Vibrating plough", Pat. 57793 Ukraine, IPC2011.01 A01B 63/111. № U201010563; claimed 31.08.2010; publ. 10.03.2011, Bul. № 5 [in Ukrainian].

[5] S. O. Filimonov, S. S. Yaschenko, A. V. Batrachenko, and N. V. Filimonova, "The use of SMART PIEZOCERAMICS for tillage in agriculture", Visnyk Cherkaskogo 
derzhavnogo tehnologichnogo universytetu, no. 2, pp. 30-36, 2019 [in Russian].

[6] I. I. Maksimov, "V. P. Goryachkin's rational formula for determination of traction resistance of the plough", in Workshop on Agricultural Machines and Tools. Cheboksary, 2011. [Online]. Available: https://studfile.net/preview/5719257/ page:33. Accessed on: Febr. 02, 2020.

[7] V. B. Samorodov, and A. Yu. Rebrov, "The development of classical methods of tractor traction calculation, taking into account the main technical and economic indicators of MTA", Visnyk Natsionalnoho tekhnichnoho universytetu "Kharkivskyi politekhnichnyi institut»: zb. nauk. prats. Тем. вип.: Автомобіле- $і$ тракторобудування, Тет. vур.: Avtomobile- $i$ tractorobuduvannya, no. 58, pp. 11-20, Kharkiv: NTU «KhPI», 2008 [in Russian].
[8] A. P. Dorokhov, E. G. Mukhamadiev, and N. A. Pecherczev (comp.), Guidelines for the implementation of the test work on the course "Operation of the machine-tractor park" (for students of the faculty of correspondence education). Chelyabinsk: ChGAA, 2010 [in Russian].

[9] A. Yu. Popov, Machines and equipment in crop production: textbook. Zernograd: Azovo-Chernomorskij inzhen. in-t FGBOU VO Donskoj GAU, 2016 [in Russian].

[10] N. A. Yazy`kov, A. A. Toporov, L. I. Rubleva, and V. Yu. Levandovskij, "Modeling of hydrodynamic processes in a reactor to intensify the chemical treatment of wastewater from phenols using the SolidWorks Flow Simulation software module", Naukovi praczi Donecz`kogo naczional nogo tekhnichnogo universitetu». Seriya "Khimiya $i$ khimicheskaya tekhnologiya», iss. 14, 2012 [in Russian].

S. O. Filimonov, Ph. D., associate professor, e-mail: s.filimonov@chdtu.edu.ua

\section{S. S. Yashchenko,}

O. V. Batrachenko, Ph. D., associate professor, e-mail:avbatrachenko1980@gmail.com

N. V. Filimonova, $P$ h. D., senior lecturer

e-mail:nv.filimonova2015@gmail.com

Cherkasy State Technological University

Shevchenko blvd, 460, Cherkasy,18006, Ukraine

\section{CALCULATION OF THE FORCES APPEARING AT THE CREATION OF VIBRATIONS BY SMART PIEZOCERAMICS, AND RESEARCH OF THEIR DISTRIBUTION IN PLOUGH DUMP}

The main purpose of this article is to calculate and determine the necessary force of smart piezoceramics to create vibrations in the plough dump and to perform simulations on the basis of the calculations.

Agriculture is providing the population with food and raw materials for a number of industries. That is why this industry is one of the most important economic spheres present in almost all countries. One of the major problems of agriculture consists in the complexity and efficiency of land cultivation. By energy costs, ploughing is the most energy-intensive operation in technological process of growing crops.

In known general purpose hinged ploughs, bolts are attached to the frame by the risers of the plow housings with the housing. During operation of the tiller unit, the traction resistance of the plough produces vibrations that increase the dynamic loads of the components and parts, which lead to their premature destruction. In addition, during oscillatory movements of the tiller unit, the tractor's efforts to move it increase, which leads to increased traction resistance. Improvement of some characteristics aggravates others, in this case when adding additional mechanical devices, their characteristics and disadvantages are placed on the soil tillage plough itself. 
Determination of the required force to create vibrations in the plough, as well as its own plough oscillations is considered. To determine the force generated, it is necessary to know the magnitude of the force, the oscillation frequencies that appear and act on the plough during ploughing.

Thus, in the work, calculations have been carried out to determine the necessary generated force of smart piezoceramics to create vibrations in vibroplough, which is $3.2 \mathrm{kN}$.

Based on the calculated data, we simulate the loading process in the SolidWorks software package. Results of the simulation of plough blade oscillation in SolidWorks software package at different frequencies to $107.88,212.45,583.48,774.94,874.62 \mathrm{~Hz}$ are shown. The maximum oscillation amplitude of the plough blade corresponds to a frequency of $36 \mathrm{~Hz}$.

Keywords: research, agriculture, vibration technologies, modeling, smart piezoceramics, calculations, working principle, analysis, food security, problems, solutions.

Стаття надійшла 09.02.2020

Прийнято 20.02.2020 